\title{
Assessing The Level Of Macroeconomic Stability Of EU Countries
}

\author{
https://doi.org/10.21272/sec.4(4).175-182.2020.
}

Andrii Zolkover, ORCID: https://orcid.org/0000-0002-8176-1850

$\mathrm{PhD}$, Doctoral Student, the Department of Business Economics and Tourism, Kyiv National University of Technologies and Design, Ukraine

Jurij Renkas, ORCID: https://orcid.org/0000-0001-7139-5458

$\mathrm{PhD}$, Assistant professor, the Department of Accounting, Cracow University of Economics, Cracow, Poland

\begin{abstract}
This article is devoted to the development of methods for assessing the integrated level of macroeconomic stability of the country. Systematization of literature sources and approaches to determining the factors influencing macroeconomic stability and methods of its assessment showed that this problem is still unresolved and needs attention, given the epidemiological threats as additional factors destabilizing the world economy. The urgency of solving this scientific problem lies in need of an adequate and timely response to changes in the development of the national economy to prevent them from escalating into crisis phenomena. The study of assessing the integrated level of macroeconomic stability in the country was carried out in the article in the following logical sequence: 1) the formation of the statistical base of the study in terms of three groups of indicators: stimulants, disincentives and nominators; 2 ) bringing the indicators of the statistical input base of the study to a comparable form; 3 ) determining the priority of the impact of the components of the indicator in the integrated indicator; 4) assessment of the integrated level of macroeconomic stability, considering both the ranking of input indicators and the strength of their impact on the formation of the desired integrated indicator; 5) conducting a qualitative interpretation of the integrated level of macroeconomic stability. The methodological tools of the study were the following methods: minimax approach to the normalization of the statistical base of the study; sigma-limited parameterization method and Pareto method for determining the priority of the impact of the components of the indicators of the integrated level of macroeconomic stability; Erlang's formula for estimating the integrated level of macroeconomic stability. The study period was 2006-2019. The countries selected for the study were the following: Poland, the Czech Republic, Lithuania, Latvia, Hungary and Slovakia. The article presents the results of the assessment of the integrated indicator, which showed that Lithuania, Latvia, the Czech Republic and Poland achieved macroeconomic stability on average from 2014 at $84 \%$, Slovakia - 65\%, while Hungary had relative stability from 2010 to 2016 , at the level of $76-82 \%$, but in $2017-2018$ there is a destabilization of economic development to $45 \%$. The results of the study can be useful for public authorities in determining macroeconomic stability as an element of national economic management, the use of which will protect against financial and economic crises by taking a set of preventive measures.
\end{abstract}

Keywords: Pareto diagram, macroeconomic stability, minimax approach, ranking, sigma-limited parameterization, Erlang's formula.

JEL Classification: E63.

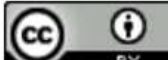

This work is licensed under a Creative Commons Attribution 4.0 International License.

Cite as: Zolkover, A., Renkas, J. (2020). Assessing The Level Of Macroeconomic Stability Of EU Countries. SocioEconomic Challenges, 4(4), 175-182. https://doi.org/10.21272/sec.4(4).175-182.2020.

(C) The Authors, 2020. This article is published with open access at Sumy State University.

\section{Introduction}

The rapid development of globalization and convergence processes in the financial sphere, the strengthening of cooperation between countries in foreign economic activity and the free movement of labour inevitably affect the 
state of macroeconomic stability in the country. Macroeconomic stability is the basis for sustainable economic growth, so its support is one of the most critical tasks not only of the central bank but also of other government regulators and supervisors. The concept of macroeconomic stability very often means constant economic growth without sharp recessions and ups and downs, accompanied by low inflation, employment, the strength of the national exchange rate. But in practice, this is not enough, especially in a pandemic and the transformation of socio-economic, behavioural patterns that accompany the world economy. For example, the official exchange rate increased from UAH $23.7(07.01 .2020)$ to UAH $28.5(01.12 .2020)$ per 1 US dollar, which is an increase of $20 \%$. In 2020, there was a decrease in the welfare of the population in Ukraine; namely, real wages decreased, and revenues from abroad decreased. However, according to the National Bank of Ukraine in 2020, there is relative financial stability. Thus, to monitor the current state of economic development of the country and identify structural imbalances in the real and financial sectors of the economy, the result of a summary indicator becomes objectively necessary.

\section{Literature review}

The analysis of research in terms of finding factors influencing the macroeconomic stability of the country is quite relevant among scientists around the world. For example, the paper (Bilan et al., 2019) proved that the macroeconomic stability of a country largely depends on the strategic decisions of the government and the transition to long-term goals can significantly increase the level of stability in the country. The study (Brunilda, Duraj et al., 2015) is based on the definition of macroeconomic determinants for stable economic growth in terms of commercial banks. Also, the policy of the country's central bank plays an essential role in ensuring the development of the national economy (Dudchenko, 2020). The paper (OSEI, 2018) on the example of Ghana contains proof of the fact that the accumulation of foreign exchange reserves is the key to increasing investment attractiveness and economic growth. Scholars examine the dynamic relationship between foreign investment inflows and a country's overall economic development (Toyin, \& Oludayol, 2020). Noteworthy is the work that examines in detail the relationship between macroeconomic stability and fiscal policy, which can be both cyclical and discretionary (Munir, K., \& Riaz, N., 2019). Also, scientists (Stanciu, 2019) have built a causal chain based on financial stability as a result of macroeconomic stability and economic security of the country. The authors (Nela et al., 2019) analyze labour market flexibility as a mandatory determinant of a country's stability. A study by Jayawickrema, 2019 proved that the tools of state regulation of inflation are an effective way to achieve stability in the country. Researchers (Palienko \& Lyulyov, 2018) have developed an indicator that prioritizes the social determinants of the development of potential human capital given the impact on the macroeconomic stability of the state.

The scientific community also pays close attention to building relationships between individual industries and overall macroeconomic stability. Accordingly, Eddassi, 2020 examines the experience of resource-rich countries in using fiscal policy instruments to minimize the negative impact of the global crisis on the development of the national economy. This issue was analyzed in more detail by Awujola et al., 2020, examining the economic situation of Nigeria, a country that is very sensitive to fluctuations in oil prices. The paper (Zolkover, \& Terziev, 2020) conducted a fundamental analysis of current research in the field of the shadow economy and emphasized that this concept in most scholars is associated with the informal economy, macroeconomic stability and unemployment. Also, the impact of the tax burden on the development of the mining industry and its consequences on the macroeconomic stability of the whole state is considered (Miller, 2019). The article examines the relationship between decentralization processes and investment attractiveness on the example of 12 European countries (Molotok, 2020). According to Reshetnikova et al. (2020) and the basis of state stability is the effective functioning of the real sector of the economy. The authors consider social entrepreneurship as a driving force for innovation, which is the key to achieving macroeconomic stability (Zainea et al., 2020). Other researchers (Jafarzadeh, \& Shuquan 2019) point out that poverty has been declining in the world in recent years, but that this shift has not occurred in developing countries, indicating an increase in income inequality in the world as a whole. The article (Bhowmik, 2020) provides practical recommendations for the formation of innovative fiscal policy to increase the share of agriculture and related industries during the economic downturn, which will stabilize in a recession. Scientists (Shymon, S. et al., 2020) have empirically proven the absence of a significant difference 
between the concepts of macroeconomic stability and economic security of the country, which are assessed by different sets of factors. Scientists such as Rahmanov et al., 2020, suggest ways to overcome the adverse epidemiological effects on some areas of society. Thus, the question of finding factors and tools for assessing the level of macroeconomic stability of the country is still unresolved, because there are many prisms through which to look at this problem.

\section{Research methodology}

Determining the general characteristics of the country's macroeconomic stability involves the gradual implementation of the following steps.

1 stage. The choice of indicators for assessing the macroeconomic stability of the country in the dynamics of $t$ years. Within the framework of this study, it is proposed to analyze the presence of imbalances in the development of the national economy based on 14 indicators (according to the methodology for determining macroeconomic imbalances in the EU), which are further grouped into a single comprehensive indicator - the level of macroeconomic stability.

To ensure the information unidirectionality of the selected indicators at the initial stage, it is advisable to divide them into three groups:

$>$ stimulants: (net international investment position to GDP (NIIP), - export market shares (EMS), activity rate $-\%$ of total population aged $15-64$ (AR);

$>$ disincentives (nominal unit labour cost (NULC), house price index - deflated price index - deflated (HPI), private sector credit flow - consolidated (PSCF), private sector debt - consolidated (PSD), general government sector debt (GGSD), unemployment rate (UR), total financial sector liabilities (TFSL), long-term unemployment rate - \% of active population aged 15-74 (LTUR), youth unemployment rate - \% of active population aged 15-24 (YUR));

$>$ nominators (current account balance to GDP (CAB), real effective exchange rate (REER)).

Indicators stimulators increase the level of the desired integrated indicator, disincentives - on the contrary, with a decrease will contribute to the growth of an integrated indicator of macroeconomic stability. At the same time, the nominators have normatively defined as the minimum and maximum possible levels.

Stage 2. Bringing the indicators of the statistical input base of the study to a comparable form based on the use of a minimax approach to their normalization. Thus, in particular, for indicators of stimulants that have a maximum allowable maximum normative value, the normalization formula takes the form:

$$
\tilde{s}_{i t}=\left\{\begin{array}{l}
\frac{s_{i t}-\min _{t} s_{i t}}{\max _{t} s_{i t}-\min _{t} s_{i t}} \\
1,\left[\begin{array}{l}
s_{i t} \geq s_{\text {inormmax }} \\
s_{i t} \leq s_{\text {inormmin }}
\end{array}\right.
\end{array}\right.
$$

where $\tilde{s}_{i t}$ is the normalized value of the $\mathrm{i}$-th indicator of macroeconomic stability assessment for the $t$-th year; $s_{i t}$ is the actual value of the $i$-th indicator of macroeconomic stability assessment for the $t$-th year;

$s_{\text {inormmax }}$ is the maximum possible normative value of the $\mathrm{i}$-th indicator of macroeconomic stability assessment; $\mathrm{s}_{\text {inormmin }}$ is the minimum possible normative value of the $\mathrm{i}$-th indicator of macroeconomic stability assessment; $\min _{t} s_{i t}$ is the minimum possible value of the $i$-th indicator of macroeconomic stability assessment for the studied time range;

$\max _{t} s_{i t}$ is the maximum possible value of the $i$-th indicator of macroeconomic stability assessment for the studied time range; 
In turn, for indicators of disincentives, which have the maximum allowable minimum normative value, the normalization formula takes the form:

$$
\tilde{s}_{i t}=\left\{\begin{array}{l}
\frac{\max _{t} s_{i t}-s_{i t}}{\max _{t} s_{i t}-\min _{t} s_{i t}} \\
1,\left[\begin{array}{l}
s_{i t} \geq s_{\text {inormmax }} \\
s_{i t} \leq s_{\text {inormmin }}
\end{array}\right.
\end{array}\right.
$$

where $\max _{t} s_{i t}$ is the the maximum possible value of the $i$-th indicator of macroeconomic stability assessment for the studied time range.

For indicators-nominators the mathematical relation which allows to bring them in a comparable kind is presented by the following formula:

$$
\tilde{s}_{i t}=\left\{\begin{array}{l}
\frac{\max _{t} s_{i t}-s_{i t}}{\max _{t} s_{i t}-\min _{t} s_{i t}} \\
1,\left[\begin{array}{l}
s_{i t} \leq s_{\text {inormmax }} \\
s_{i t} \leq s_{\text {inormmin }}
\end{array}\right.
\end{array}\right.
$$

where min $\left(s_{\text {inorm }}\right)$ is the minimum normative value of the $\mathrm{i}$-th indicator for assessing macroeconomic stability; $|\ldots|$ - number module.

In turn, for the classic indicator-stimulator (index of real wages, $\%$ to the previous year) for normalization used the formula:

$$
\tilde{s}_{i t}=\frac{s_{i t}-\min _{t} s_{i t}}{\max _{t} s_{i t}-\min _{t} s_{i t}}
$$

where $\min _{t} s_{i t}$ is the minimum possible value of the $i$-th indicator of macroeconomic stability assessment for the studied time range.

Stage 3. Ranking of input indicators, estimating the strength of the impact on the formation of the desired integrated indicator, as well as determining the priority of the effects of component indicators by constructing a Pareto diagram by the method of sigma-limited parameterization. To build a Pareto chart by the method of sigmalimited parameterization, there is a need to additionally involve another indicator as a performance indicator, where the indicator GDP per capita (current US \$) is selected. The Pareto diagram allows obtaining a visualization using the values of the Student's t-test of the priority of indicators. This approach refers to one of the onedimensional significance tests.

Stage 4. Determining the weights of the priority of the impact of indicators on the formation of an integrated indicator of macroeconomic stability using a combination of ranks, distinguished based on the Pareto approach and variability (standard deviation) of each of the input indicators:

$$
\mathrm{w}_{\mathrm{i}}=\frac{\left(1-\mathrm{r}_{\mathrm{i}}\right) \cdot \sigma_{\mathrm{i}}}{\sum_{\mathrm{i}}\left(1-\mathrm{r}_{\mathrm{i}}\right) \cdot \sigma_{\mathrm{i}_{\mathrm{it}}}}
$$

where $\mathrm{w}_{\mathrm{i}}$ is the weighting factor of the $\mathrm{i}$-th indicator of macroeconomic stability assessment;

$r_{i}$ is the rank of the i-th indicator of macroeconomic stability assessment, determined on the basis of the Pareto diagram by the method of sigma-limited parameterization;

$\sigma_{\mathrm{i}}$ is the the standard deviation of the $\mathrm{i}$-th indicator of macroeconomic stability. 
Stage 5. Estimation of the integrated level of macroeconomic stability based on Erlang's formula, which takes into account both the ranking of input indicators and the strength of influence on the formation of the desired integrated indicator based on the appropriate degree of its normalized value and weighting of the relevant rank:

$$
\mathrm{IEI}_{\mathrm{t}}=\left(1+\frac{\widetilde{\mathrm{m}}_{1 \mathrm{t}}}{1 !}+\frac{\left(\widetilde{\mathrm{m}}_{2 \mathrm{t}}\right)^{2}}{2 !}+\frac{\left(\widetilde{\mathrm{m}}_{3 \mathrm{t}}\right)^{3}}{3 !}+\cdots+\frac{\left(\widetilde{\mathrm{m}}_{11 \mathrm{t}}\right)^{11}}{11 !}\right)^{-1}
$$

where $\mathrm{IEI}_{\mathrm{t}}$ is the integrated indicator of macroeconomic stability by the Erlang's method for the $\mathrm{t}$-th year;

$\widetilde{\mathrm{m}}_{1 \mathrm{t}}$ is the normalized value of the first in rank (based on the Pareto diagram by the method of sigma-limited parameterization) indicator of macroeconomic stability for the $t$-th year;

1 ! is one factorial;

$\widetilde{\mathrm{m}}_{2 \mathrm{t}}$ is the normalized value of the second-ranked (based on the Pareto diagram by the method of sigma-limited parameterization) indicator for assessing macroeconomic stability for the $t$-th year;

2 ! is two factorial.

Stage 6. Qualitative interpretation of the integrated level of macroeconomic stability in terms of four possible interval limits: high, above average, medium and low:

$$
\left\{\begin{array}{c}
\text { high, if } \mathrm{IEI}_{\mathrm{t}} \geq 0,75 \\
\text { above average, if } 0,50 \leq \mathrm{IEI}_{\mathrm{t}}<0.75 \\
\text { average, if } 0,25 \leq \mathrm{IEI}_{\mathrm{t}}<0.50 \\
\text { low, if } \mathrm{IEI}_{\mathrm{t}}<0.25
\end{array}\right.
$$

\section{Results}

The methodology for assessing the integrated level of macroeconomic stability has been tested based on data indicators of socio-economic development of such countries as Poland, the Czech Republic, Lithuania, Latvia, Hungary and Slovakia. The study period is 2006-2019. The source of statistical information on macroeconomic imbalances in the context of the European Union is Eurostat data.

Based on the use of the minimax approach, the input data array was normalized, which allowed reducing the indicators to a single comparable form, ranging from 0 to 1. (4), are presented in Table 1.

Table 1. Normalized values of indicators for assessing the macroeconomic stability of Poland (study fragment)

\begin{tabular}{|c|c|c|c|c|c|c|c|c|c|c|c|c|c|c|}
\hline Year & CAB & NIIP & REER & EMS & NULC & HPI & PSCF & PSD & GGSD & UR & TFSL & AR & LTUR & YUR \\
\hline 2006 & 0.30 & 0.80 & 0.17 & 1.00 & 1.00 & 0.21 & 1.00 & 1.00 & 1.00 & 0.00 & 0.00 & 0.10 & 1.00 & 1.00 \\
\hline 2007 & 0.25 & 0.83 & 0.00 & 1.00 & 1.00 & 0.00 & 1.00 & 1.00 & 1.00 & 0.24 & 0.28 & 0.00 & 1.00 & 1.00 \\
\hline 2008 & 0.00 & 0.57 & 0.09 & 1.00 & 0.12 & 1.00 & 0.00 & 1.00 & 1.00 & 0.52 & 1.00 & 0.07 & 1.00 & 1.00 \\
\hline 2009 & 0.02 & 0.50 & 1.00 & 1.00 & 0.00 & 1.00 & 1.00 & 1.00 & 1.00 & 1.00 & 1.00 & 1.00 & 1.00 & 1.00 \\
\hline 2010 & 0.09 & 0.18 & 1.00 & 1.00 & 0.08 & 1.00 & 1.00 & 1.00 & 1.00 & 1.00 & 1.00 & 1.00 & 1.00 & 0.23 \\
\hline 2011 & 0.18 & 0.28 & 0.00 & 1.00 & 1.00 & 1.00 & 1.00 & 1.00 & 1.00 & 1.00 & 1.00 & 1.00 & 0.04 & 0.00 \\
\hline 2012 & 0.18 & 0.16 & 1.00 & 1.00 & 1.00 & 1.00 & 1.00 & 1.00 & 1.00 & 1.00 & 1.00 & 1.00 & 0.00 & 0.09 \\
\hline 2013 & 1.00 & 0.00 & 1.00 & 1.00 & 1.00 & 1.00 & 1.00 & 1.00 & 1.00 & 0.53 & 1.00 & 1.00 & 0.02 & 0.17 \\
\hline 2014 & 1.00 & 0.00 & 1.00 & 1.00 & 1.00 & 1.00 & 1.00 & 1.00 & 1.00 & 1.00 & 1.00 & 1.00 & 1.00 & 1.00 \\
\hline 2015 & 1.00 & 0.30 & 1.00 & 1.00 & 1.00 & 1.00 & 1.00 & 1.00 & 1.00 & 1.00 & 1.00 & 1.00 & 1.00 & 1.00 \\
\hline 2016 & 1.00 & 0.32 & 0.77 & 1.00 & 1.00 & 1.00 & 1.00 & 1.00 & 1.00 & 1.00 & 1.00 & 1.00 & 1.00 & 1.00 \\
\hline 2017 & 1.00 & 0.34 & 1.00 & 1.00 & 1.00 & 1.00 & 1.00 & 1.00 & 1.00 & 1.00 & 1.00 & 1.00 & 1.00 & 1.00 \\
\hline 2018 & 1.00 & 0.55 & 1.00 & 1.00 & 1.00 & 1.00 & 1.00 & 1.00 & 1.00 & 1.00 & 1.00 & 1.00 & 1.00 & 1.00 \\
\hline 2019 & 1.00 & 0.82 & 1.00 & 1.00 & 0.22 & 0.74 & 1.00 & 1.00 & 1.00 & 1.00 & 1.00 & 1.00 & 1.00 & 1.00 \\
\hline
\end{tabular}

Source: compiled by author.

After normalization of the statistical input base of the study, there is a need for further ranking, assessing the strength of the impact on the formation of the desired integrated indicator, as well as determining the priority of 
the effect of composite indicators by constructing a Pareto diagram by sigma-limited parameterization. Systematization of the results of Pareto charts in terms of Poland, the Czech Republic, Latvia, Lithuania, Hungary and Slovakia is presented in Table 2.

Table 2. Systematization of the results of significance/insignificance of indicators for assessing macroeconomic stability and their ranking

\begin{tabular}{|c|c|c|c|c|c|c|}
\hline Indicator & Poland & $\begin{array}{l}\text { The Czech } \\
\text { Republic }\end{array}$ & Lithuania & Latvia & Hungary & Slovakia \\
\hline $\mathrm{CAB}$ & Significant, 1 rank & Significant, 4 rank & Significant, 6 rank & Significant, 4 rank & Significant, 8 rank & Significant, $11 \mathrm{rank}$ \\
\hline NIIP & Significant, 5 rank & Significant, $11 \mathrm{rank}$ & Significant, 9 rank & Significa & t, $11 \mathrm{rank}$ & 2 rank \\
\hline REER & gnificant, 7 rank & 8 rank & & & & \\
\hline EMS & $11 \mathrm{rank}$ & Signific & & & & \\
\hline NULC & Significe & Signific & Signif & Sig & Signi & , 9 rank \\
\hline & t, 6 rank & 9 rank & & & & \\
\hline PSCF & Significant, 3 rank & Signific & & & t, 7 rank & t, 3 rank \\
\hline PSD & Significant, 8 rank & t, 1 rank & Signif & Signific & $\mathrm{t}, 10 \mathrm{rank}$ & $10 \mathrm{rank}$ \\
\hline GGSD & 4 rank & & & & & \\
\hline UR & $10 \mathrm{rank}$ & Signific & & Significant, 9 rank & t, 3 rank & t, 7 rank \\
\hline TFSL & t, 2 rank & Significa & Sig & Significant, 2 rank & Significant, 12 rank & Significant, 6 rank \\
\hline & it, 9 rank & Signific & Significant, 1 rank & Significant, 8 rank & Significant, 2 rank & \\
\hline LTUR & t, 12 rank & Signific & Significant, 2 rank & Significant, 12 rank & Signifi & \\
\hline YUR & Insignificant & Insignificant & Insignificant & Significant, 13 rank & Insignificant & Significant, 12 rank \\
\hline
\end{tabular}

Source: compiled by author.

At the last stage, we will assess the integrated level of macroeconomic stability based on Erlang's formula, which takes into account the ranking of input indicators, as well as a qualitative interpretation of the integrated level of macroeconomic stability in terms of four possible intervals: high, above average, medium and low. The results of the calculation of the integrated indicator of macroeconomic stability of Erlang are presented in Figure 1.

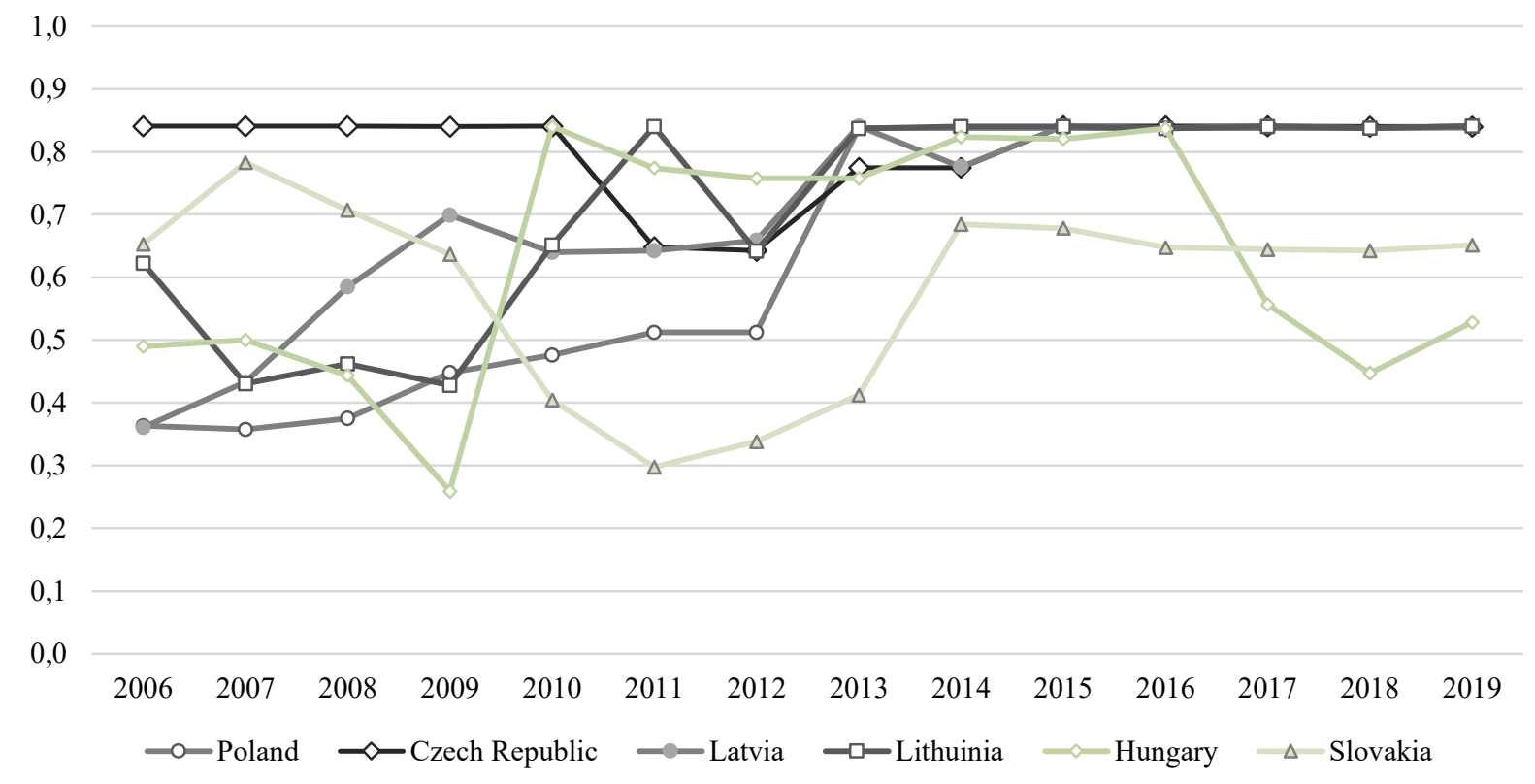

Figure 1. The dynamics of the level of macroeconomic stability of the EU countries during 2006-2019

Source: compiled by author. 
The data in Figure 1 show that as of 2019, four countries (Poland, the Czech Republic, Latvia, Lithuania) have a high level of macroeconomic stability, while Hungary and Slovakia are above average. Most of the analyzed countries are characterized by a decrease in macroeconomic stability in the period from 2011 to 2013. It is worth noting that during 2006-2019 the level of macroeconomic stability in the Czech Republic was always above average, which indicates an effective state economic policy and balanced development of the economic and social sphere.

\section{Conclusions}

The proposed methodology for building a general indicator of macroeconomic stability can serve as a tool for monitoring current and future changes in the national economy to take a set of preventive measures to minimize risks and prevent crises in the development of real and financial sectors of the economy. As a result of this study, a comparative analysis of 14 determinants was conducted, which allow to identify the manifestations of macroeconomic imbalances in the development of the national economy of the country. The constructed Pareto charts made it possible to rank the factors influencing macroeconomic stability according to the level of their significance for each state, and then to generalize them to determine the integrated indicator by the Erlang method. The result of the analysis of the obtained indicators is that Lithuania, Latvia, the Czech Republic and Poland have achieved some stability since 2014 at an average of $84 \%$, Slovakia has also achieved stability, but at $65 \%$. As for Hungary, it had relative stability from 2010 to 2016 at $76-82 \%$, but in $2017-2018$ there was a destabilization of economic development to $45 \%$. The priority areas of further research are to assess the impact of economic shadowing on the level of macroeconomic stability of the country.

Funding: self-funded.

Author Contributions: conceptualization, Andrii Zolkover, Venelin Terziev; methodology, Andrii Zolkover, Venelin Terziev; validation, Andrii Zolkover, Venelin Terziev; formal analysis, Andrii Zolkover Venelin Terziev; investigation, Andrii Zolkover Venelin Terziev; resources, Andrii Zolkover Venelin Terziev; data curation, Andrii Zolkover Venelin Terziev; writing original draft preparation, Andrii Zolkover Venelin Terziev; writing review and editing, Andrii Zolkover Venelin Terziev; visualization, Andrii Zolkover Venelin Terziev; supervision, Andrii Zolkover Venelin Terziev; project administration, Andrii Zolkover Venelin Terziev.

\section{References}

1. Awujola, A., Iyakwari, A. D. B., Bot, R. E. (2020). Examination Of The Relationship Between Oil Price Shock And Macroeconomic Variables In Nigeria. SocioEconomic Challenges, 4(1), 102-110. http://doi.org/10.21272/sec.4(1).102-110.2020.

2. Bhowmik, D. (2020). Trends, Cycles and Seasonal Variations of Ukrainian Gross Domestic Product. Financial Markets, Institutions and Risks, 4(3), 80-94. https://doi.org/10.21272/fmir.4(3).8094.2020 .

3. Bilan, Y., Lyeonov, S., Lyulyov, O., \& Pimonenko, T. (2019) Brand management and macroeconomic stability of the country. Polish Journal of Management Studies, 19(2), 61-74. DOI: 10.17512/pjms.2019.19.2.05.

4. Dudchenko, V. (2020). Role of Central Bank Independence in Banking and Financial Stability Ensuring. Financial Markets, Institutions and Risks, 4(2), 115-121. https://doi.org/10.21272/fmir.4(2).115$\underline{121.2020 .}$.

5. Duraj, B., \& Moci, E. (2015). Factors influencing the bank profitability - empirical evidence from Albania Asian Economic and Financial Review, 5(3), 483-494. DOI: 10.18488/journal.aefr/2015.5.3/102.3.483.494.

6. Eddassi, H. (2020). Fiscal Regime and Tax Policy in Resource-Rich Countries In The Process Of $\begin{array}{llll}\text { Globalization: } \quad \text { Literature } & \text { Review. SocioEconomic }\end{array}$ https://doi.org/10.21272/sec.4(2).67-77.2020.

7. Jayawickrema, V. (2019). Monetary Policy Rules and Macroeconomic Stability. SSRN Electronic Journal. https://doi.org/10.2139/ssrn.3443113. 
8. Jafarzadeh, E., \& He, Shuquan (2019). The Impact of Income Inequality on the Economic Growth of Iran: An Empirical Analysis. Business Ethics and Leadership, 3(2), 53-62. http://doi.org/10.21272/bel.3(2).53$\underline{62.2019 .}$

9. Nela, D., Armend, M., \& Hasan, M. (2019) Macroeconomic Stability and Labour Market Efficiency in Kosovo: A Competitiveness Approach. IFAC-Papers, 52(25), 142-147. https://doi.org/10.1016/j.ifacol.2019.12.462.

10. Osei, D. (2018) Dynamics of foreign exchange reserves accumulation and macroeconomic stability: the Ghanaian perspective. Aziya i Afrika Segodnya, Issue 10, 61-65. DOI: 10.31857/S032150750001018-1.

11. Palienko, M., Lyulyov, O. (2018). The Impact of Social Factors on Macroeconomic Stability: Empirical Evidence for Ukraine and European Union Countries. SocioEconomic Challenges, 2(1), 103-116. DOI: 10.21272/sec.2(1).103-116.2018.

12. Stanciu, L. (2019). Financial Stability - Fundamental Pillar of Macroeconomic Balance and Stability. International conference knowledge-based organization, 25(2), 93-97. https://doi.org/10.2478/kbo-2019-0062.

13. Macroeconomic imbalance Procedure. Eurostat. URL: Indicators - Macroeconomic Imbalance Procedure Eurostat (europa.eu). Available at: https://ec.europa.eu/eurostat/web/macroeconomic-imbalancesprocedure/indicators.

14. Miller, A.D. (2019). Current Mining Taxation Policy Implemented by both Mongolia and Kazakhstan: The Development Comparatives between Ulaanbaatar and Astana. Business Ethics and Leadership, 3(2), 39-52. http://doi.org/10.21272/bel.3(2).39-52.2019.

15. Molotok, I. (2020). Analysis Of The Relevance Of Fiscal Decentralization In Ensuring Country Investment Attractiveness. SocioEconomic Challenges, 4(2), 99-105. https://doi.org/10.21272/sec.4(2).99-105.2020.

16. Munir, K., \& Riaz, N. (2019). Fiscal Policy and Macroeconomic Stability in South Asian Countries. Revista Hacienda Pública Española, 228(1), 13-33. https://doi.org/10.7866/hpe-rpe.19.1.1.

17. Reshetnikova, I., Shvydanenko, H., \& Boichenko, K. (2020). Determinants to Provide the Efficiency of Integrated Development of the Light Industry Enterprises. Marketing and Management of Innovations, 3, 157-169. http://doi.org/10.21272/mmi.2020.3-11.

18. Shymon, S., Kolomiets-Ludwig, E., Osiejewicz, Jo., Krawczyk, D. \& Kaminska, B. (2020). The Role of Country Brand in Providing Economic Resilience. Marketing and Management of Innovations, 1, 303-311. http://doi.org/10.21272/mmi.2020.1-26.

19. Toyin, O.W., Oludayol Ad., E. (2020). Dynamic Effects of Foreign Portfolio Investment on Economic Growth in Nigeria .Financial Markets, Institutions and Risks, 4(3), 512. https://doi.org/10.21272/fmir.4(3).5-12.2020.

20. Zainea, N. L., Toma, S.G., Grădinaru, C., Catană, S. (2020). Social Entrepreneurship, a Key Driver to Improve the Quality of Life: The Case of TOMS Company. Business Ethics and Leadership, 4(3), 6572. https://doi.org/10.21272/bel.4(3).65-72.2020.

21. Zolkover, A., Terziev, V. (2020). The Shadow Economy: A Bibliometric Analysis. Business Ethics and Leadership, 4(3), 107-118. https://doi.org/10.21272/bel.4(3).107-118.2020. 